
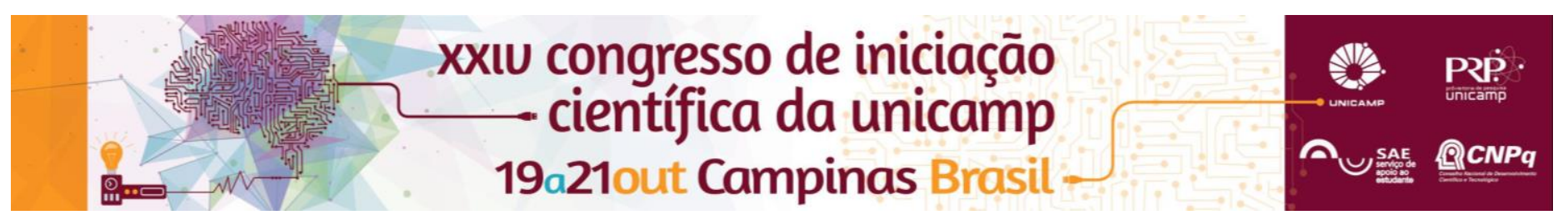

\title{
Walkability: concept and application
}

\author{
Rafael Marengoni (IC), Gisela Cunha Viana Leonelli (PQ) \\ Grupo CNPq: GEURU - Grupo de Estudos de Urbanização e Regulação Urbana
}

\begin{abstract}
Walkabiltiy is the term used within the field of urban planning, design and architecture to describe the relationship between urban spaces and pedesetrians, and also walking as a behavioural issue. The goal of this research is to further investigate the concept of Walkability and to attempt to apply it in a neighborhood of Campinas, to verify feasibility for a brazilian context.
\end{abstract}

\begin{abstract}
Key words:
urban design, urban planning, walkability
\end{abstract}

\section{Introduction}

The term Walkability has been increasingly used when referring to urban planning or design schemes with the intent of creating an urban environment that joins people and their daily activities. This research's main goal is to comprehend walkability as a concept, and also, to understand how it has been applied through public policy in Melbourne, Australia. This investigation contributes to the overall understanding of how a concept can be implemented through urban planning, design, strategies and projects. By reviewing the existing literature on the subject it was possible to outline the key urban elements that would make a place walkable, and by looking into the planning policy outlines and strategies for Melbourne over the past 20 years, a way of promoting these key urban elements could be observed. The final stage of this project is to elaborate a pilot urbanistic intervention for an area in the city of Campinas that considers walkability as its main objective. To improve urban spaces it is fundamental to comprehend the concept and application of walkability.

\section{Results and Discussion}

By reviewing the existing literature on the subject different categories were created according to the approach chosen by different authors on the matter, these categories are: "classics", "specialists" and "public health". Through the analysis of of the authors comprised within these categories it would be possible to draw correlates between the different views and criteria on walkabiltiy. A study to define walkabilty carried out by Stephen Spoon (2005) selected a series of authors on the subject along with their definitions and proceeded to create a hierarchical structure of elements that would bey key to defining walkability. This structure presented three categories, the essential elements, the encouraged and the extra. In this structure he notes mixeduse urban areas, the populational density of an area, street connectivity, pedestrian infrastructure, accessibility, amongst other qualities. It is interesting to notice that these same elements appear in the work of other authors, when referring to desirable urban qualities, that do not mention the word "walkability". This is the case of Jan Gehl, danish architect and urbanist, an international specialises in urban intervention consultancy. In his works, Gehl emphasizes the importance of the human scale within the urban context, and if the working definition of walkability were to be considered to classify Gehl's approach a overlapping of ideas would occur, meaning that Gehl's approach is an application of walkability. Not only has Gehl been relevant to this research from his contributions to defining walkability, but also for his work with Gehl Architects in Melbourne, this research's case study. Gehl worked for the City of Melbourne in a strategic intervention to improve public life in public spaces, in other words, improving the quality of urban spaces. After the 1994 report on Melbourne a series of the recommendations could be found in the public policy planning agenda and it still can be found to this day. Melbourne's international celebrity as the most livable city in the world can be correlated with these planning strategies, which reinforces the relevance of understanding possible applications of walkability.

\section{Conclusions}

So far, a deeper comprehension of walkability could be estabilished. It is an ideology and vision for practice as well as a quality of the built environment. Also, it has been found that many authors considered classics in the urban planning/design field, already discussed walkability issues without using the world walkability. As for the case study, it is clear that walkability was deliberately planned over the course of the years in Melbourne by specific directions within the planning outlines.

\section{Acknowledgement}

I thank Fapesp for funding this research, and also Gisela, my advisor for the support.

SPOON, S.C. (2005). What defines walkability. University of North Carolina at Chapel Hill (Dissertação de mestrado)

GEHL, J.(2010). Cities for people. Island Press. Copenhagen.

JACOBS, J.(1961) The Death and Life of Great American Cities.

Random House, New York 